\title{
BIOGRAFIA, GÊNERO E CARNAVAL: UMA RAINHA NOS FESTEJOS DE MOMO NA PORTO ALEGRE DO INÍCIO DO SÉCULO XX
}

\author{
Caroline Pereira Leal
}

\begin{abstract}
Resumo: O carnaval de Porto Alegre, no início do século XX, - representado pelas sociedades carnavalescas Esmeralda e Venezianos - é marcado por transformações que podem ser entendidas através da ótica dos estudos de gênero. De Evas pecadoras, as mulheres passaram a figurar como Marias, recatadas e redentoras. Mas quem eram essas mulheres? O presente artigo busca dar voz a Elvira Werna Coelho, que em 1911 foi rainha da Sociedade Carnavalesca Os Venezianos, apresentando alguns aspectos de sua trajetória de vida. Procuro com este trabalho não só conhecer Elvira Werna Coelho, mas também dar visibilidade às mulheres enquanto sujeitos históricos e lançar luz sobre as demais mulheres, refletindo sobre sua participação no carnaval em Porto Alegre.
\end{abstract}

Palavras-chave: Biografia. Carnaval. Gênero. História das Mulheres. Porto Alegre.

\section{BIOGRAPHY, GENDER AND CARNIVAL: A QUEEN AT THE MOMO FESTIVALS IN PORTO ALEGRE IN THE EARLY 20th CENTURY}

\begin{abstract}
Porto Alegre's Carnival, at the beginning of the 20th century, represented by the societies Esmeralda and Venezianos, is marked by transformations that can be understood from the perspective of gender studies. From sinful Evas, the women came to appear as Marias demure and redemptive. But who were these women? This article seeks to give voice to Elvira Werna Coelho, who in 1911 was the queen of the Sociedade Carnavalesca Os Venezianos, presenting some aspects of her life trajectory. I seek not only to meet Elvira Werna Coelho but also to give visibility to women as historical subjects and to shed light on the other women who made carnival in Porto Alegre.
\end{abstract}

Keywords: Biography. Carnival. Genre. Women's history. Porto Alegre.

\section{BIOGRAPHIE, GENRE ET CARNAVAL: UNE REINE AUX FESTIVALS DE MOMO À PORTO ALEGRE AU DÉBUT DU XXe SIÈCLE}

Résumé: Le carnaval de Porto Alegre, au début du XXe siècle, représenté par les sociétés Esmeralda et Venezianos, est marqué par des transformations qui peuvent être comprises dans la perspective des études de genre. Des Evas pécheurs, les femmes en sont venues à apparaitre comme des Marias sobres et rédemptrices. Mais qui étaient ces femmes ? Cet article cherche à donner la parole à Elvira Werna Coelho, qui en 1911 était la reine de la Sociedade Carnavalesca Os Venezianos, en présentant certains aspects de sa trajectoire de vie. Je cherche non seulement à rencontrer Elvira Werna Coelho, mais aussi à donner une visibilité aux femmes en tant que sujets historiques et à mettre en lumière les autres femmes qui ont fait le carnaval de Porto Alegre.

Mots-clés: Biographie. Carnaval. Genre. Histoire des femmes. Porto Alegre.

\footnotetext{
${ }^{1}$ Possui graduação em História (Bacharelado e Licenciatura) pela Universidade Federal do Rio Grande do Sul (2004/2005). Mestrado (2008) e Doutorado (2013) em História - Programa de Pós graduação em História da Pontifícia Universidade Católica do Rio Grande do Sul. Pesquisa a história do carnaval e das festas populares, sobretudo as questões ligadas às relações de gênero. Tem experiência em ensino superior com as disciplinas de História do Brasil III e História da África e dos Africanos no Brasil e na educação básica nas disciplinas de História, Geografia e Filosofia.
}

Revista Escritas do Tempo - v. 2, n. 6, out-dez/2020 - p. 305-329 


\section{BIOGRAFÍA, GÉNERO Y CARNAVAL: UNA REINA EN LOS FESTIVALES MOMO DE PORTO ALEGRE A PRINCIPIOS DEL SIGLO XX}

Resumen: El carnaval de Porto Alegre, a principios del siglo XX, representado por las sociedades del carnaval veneciano y Esmeralda, está marcado por transformaciones que pueden entenderse desde la perspectiva de los estudios de género. De Evas pecaminosas, las mujeres aparecieron como Marías, recatadas y redentojras. ¿Pero quiénes eran estas mujeres? Este artículo busca darle voz a Elvira Werna Coelho, quien en 1911 fue reina de la Sociedad Carnavalesca Os Venezianos, presentando algunos aspectos de su trayectoria de vida. Con este trabajo trato no solo de conocer a Elvira Werna Coelho, sino también de dar visibilidad a las mujeres como temas históricos y arrojar luz sobre otras mujeres, reflexionando sobre su participación en el carnaval de Porto Alegre.

Palabras clave: Biografía, Carnaval, Género, Historia de la Mujer, Porto Alegre.

As décadas finais do século $\mathrm{XX}$ marcaram o aumento no número de historiadores e historiadoras que passaram a se preocupar em desvendar o sentido histórico de uma vida individual e deixaram de rejeitar as biografias históricas ${ }^{2}$. Sentido histórico na medida em que, mais do que narrar os feitos de grandes homens, simplificando a trajetória de uma vida numa visão linear e teleológica, os estudos buscaram considerar as relações entre o indivíduo e a sociedade, entre o público e o privado, entre acontecimentos, conjunturas e estruturas, procurando apreender as diversas facetas da existência desse sujeito. Tratava-se de "examinar os atores (ou o ator) célebres ou não, como testemunhas, como reflexos, como reveladores de uma época. A biografia não era mais a de um indivíduo isolado, mas a história de uma época vista através de um indivíduo ou de um grupo de indivíduos" (PRIORE, 2009, p. 9). O indivíduo, assim, encontraria a história: suas paixões, seus conflitos e as representações que pesavam sobre suas condutas. Neste encontro foi possível "trazer à tona experiências de mulheres, invisíveis durante largo tempo, diante de uma História que se manteve centrada na noção de sujeito universal" (SOHIET, 2003, p. 33).

Deste modo, o presente artigo tem como objetivo utilizar a trajetória de vida de Elvira Werna Coelho, rainha da Sociedade Carnavalescas Os Venezianos (1911), como objeto de pesquisa, a fim de melhor compreender a participação das mulheres no carnaval porto-alegrense do início do século $\mathrm{XX}$, evidenciando o processo de genderização que ocorreu na festa. Meu objetivo é resgatar alguns fatos da história de vida dessa mulher que, assim como as demais rainhas, foi símbolo do carnaval. Dentro de meus limites, procurarei explorar as diversas facetas da vivência de Elvira, bem

\footnotetext{
${ }^{2}$ De acordo com Dosse (2009, p. 104), a partir dos anos 90 "historiadores eruditos, autores de biografias, já não precisam se justificar junto a seus pares por ter escolhido esse gênero, que não constitui mais objeto de depreciação".
} 
como as relações estabelecidas entre sua vida pública e a privada - o título de rainha se fez sentir nas suas experiências privadas? Até que ponto sua trajetória de vida refletiu as características que o festejo carnavalesco propalava como seus signos de distanciamento? De que forma suas relações de parentesco e o capital social por ela acumulado puderam se refletir no carnaval da capital? Acredito que sua trajetória de vida, compreendida em sua individualidade e não só como "a rainha" é uma questão que ajuda a compreender as relações existentes nesse festejo, bem como a mudança no que se refere a genderização do carnaval em Porto Alegre.

Genderização é aqui usado como substituto do termo gendered (SCOTT, 1990), aludindo a algo que é marcado por especificidades de gênero. Partilho, portanto, do conceito de gênero proposto por Scott (1990, p. 15), que o define como o saber a respeito das diferenças sexuais, "um elemento constitutivo de relações sociais fundadas sobre as diferenças percebidas entre os sexos, e [...] o primeiro modo de dar significados às relações de poder", pois esse conhecimento funda significados sobre as diferenças corpóreas, sendo primeiro campo por meio do qual o poder é articulado. Desta forma, como a própria Scott (1990, p. 16) ressalta, os "conceitos de gênero estruturam a percepção e a organização concreta e simbólica de toda a vida social” e as diferenças sobre os corpos são chamadas a "testemunhar as relações sociais e as realidades que não tem nada a ver com a sexualidade". É neste sentido que, por genderização do carnaval, entendo o processo ocorrido em Porto Alegre, a partir do último quartel do século XIX, que demarcava papeis de gênero, ao estipular diferentes lugares e condições para homens e mulheres na festa e construir distintas representações sobre as mulheres através de um simbolismo sexual que legitimava a hierarquização dos gêneros.

Sobre a historiografia do carnaval, especificamente a respeito da cidade de Porto Alegre, há de se mencionar as seguintes pesquisas: Alexandre Lazzari (1998, p. 12-13), em trabalho pioneiro, abordando o século XIX, buscou compreender a festa como uma tradição baseada em adaptações, ressignificações e rejeições das novidades culturais da Corte carioca e da Europa, "conforme suas conveniências e condições sociais e políticas". Isso, posteriormente, teria facilitado a difusão dos símbolos de identidade nacional, pois já encontraria um "terreno preparado, de diferentes formas, nos maiores centros urbanos do território nacional, onde eles não eram estranhos às classes populares". Partindo das observações propostas pelo referido autor, tanto em minha dissertação, quanto em minha tese, busquei investigar a participação das mulheres dos 
festejos carnavalescos nesse mesmo período. O presente texto é fruto de parte desses trabalhos (LEAL, 2008; LEAL, 2013).

As décadas de 1930 e 1940 do carnaval porto-alegrense foram estudadas por Íris Germano (1999) e Marcus de Freitas Rosa (2008). Abordando alguns aspectos da construção identitária negra em Porto Alegre através do estudo do carnaval, Germano enfocou os diferentes modos como os grupos afrodescendentes locais se apropriaram da festa e compuseram suas identidades como negros, porto-alegrenses, gaúchos e brasileiros. Rosa (2008, p. 6), por sua vez, buscou enfatizar a multiplicidade de sujeitos e modos de organização, a variedade de sentidos e a diversidade dos lugares da festa", olhando para a construção de hierarquias e distinções, aproximações e distanciamentos e os conflitos e solidariedades estabelecidos entre os variados agrupamentos carnavalescos da cidade, num período em que “os folguedos 'populares' foram submetidos a um intenso processo de transformação em 'ícones de brasilidade'.

No que tange à festividade celebrada no formato de Escolas de Samba, Helena Cattani (2014, p.6) analisou o processo de cariocalização do carnaval de Porto Alegre, buscando compreender como, a partir da década de 1960, foi incorporado o "modelo carioca de fazer carnaval, tornando-se esta uma das únicas formas de comemorar os dias do rei Momo". Já Laura Galli (2019) abordou o processo que desencadeou na transferência dos desfiles de Carnaval das escolas de samba do centro de Porto Alegre para a área do Porto Seco, na Zona Norte da cidade (1994-2004), buscando entender qual o lugar do Carnaval na cidade.

Para o desenvolvimento deste trabalho foram utilizadas as seguintes fontes: a imprensa escrita, como os jornais A Reforma (1875), Jornal do Comércio (1882), O Século (1883), A Federação (1886, 1891, 1892, 1909, 1911) Correio do Povo (1907, 1910, 1911), O Independente $(1905,1908,1911)^{3}$; documento oficiais, como registro de nascimento, certidão de casamento e óbito e inventários. Além disso, trabalhei com

\footnotetext{
${ }^{3}$ É interessante destacar que A Federação, fundado em 1884, era o órgão oficial do Partido Republicano Rio-grandense (PRR). Veículo de divulgação dos ideais políticos do partido, se tornou seu porta-voz quando de sua ascensão ao governo do estado. Foi extinto por decreto em 1937. O jornal Correio do Povo, criado em $1^{\circ}$ de outubro de 1895 por Francisco Antônio Vieira Caldas Júnior e ainda hoje em circulação. Destacou-se como órgão independente de vinculações partidárias, embora conservador, gozando de grande prestígio na imprensa do sul do país. E por fim, periódico $O$ Independente, folha de caráter informativo criada por Octaviano de Oliveira algum tempo após o fechamento d'A Gazetinha, circulou até 1923 (STEYER, 2010, p. 54). De acordo com Anderson Vargas, que em sua dissertação teve como objeto de pesquisa $O$ Independente, "durante todo o período pesquisado, aquele periódico revelou uma verdadeira 'ânsia de civilização', um desejo irrestrito de progresso material e, ao mesmo tempo, um monocórdio lamento sobre a 'decadência' causada pelo desejado movimento de avanço" (VARGAS, 2007, p. 2).
} 
fontes orais, como relatos de familiares. As entrevistas exploratórias foram realizadas de maneira virtual, com poucas perguntas direcionadas e mais com o objetivo de ouvir opiniões e relatos a respeito de Elvira. Assim como nos demais documentos, buscou-se nessas fontes extrair as evidências e elementos que contribuíssem para a elucidação do problema de pesquisa e não como a história em si (ALBERTI, 2004).

\section{A Genderização do Carnaval de Porto Alegre}

No fim do carnaval de 1906, uma notícia movimentou a cidade: ressurgiam Esmeralda e Venezianos. Antigas sociedades carnavalescas que, nascidas em meados do século XIX, trouxeram um novo modo de comemorar os dias de Momo. Era o carnaval veneziano, com préstitos e bailes para seus associados.

Quando de seu surgimento (1873), o objetivo dessas agremiações era modernizar e moralizar os festejos, substituindo as brincadeiras de entrudo por uma comemoração que fosse "civilizada", "moderna" e representante dos novos tempos. O entrudo foi a maneira pela qual o carnaval chegou ao Brasil, através dos colonizadores portugueses. Consistia no arremesso de limões de cheiro (esferas de cera em formato de laranjas/limão que continham água perfumada), água jogada de bisnagas, seringas, bacias e baldes, farinha, pó de arroz e vermelhão. O objetivo era mesmo molhar e sujar o adversário. A licenciosidade, contudo, era um dos principais argumentos de críticas ao entrudo e motivo para que as sociedades carnavalescas o enterrassem de vez. O velho jogo "dá[va] ao belo sexo o delírio das bacantes" (A Reforma, Porto Alegre, 18 de fevereiro de 1875), como afirmava Xicolomã, cronista do jornal A Reforma. Talvez, por esse motivo, o referido periódico alertasse para o perigo dos "abraços traiçoeiros que começam na porta da rua e iam terminar mesmo nas barbas dos senhores pais de família" (A Reforma, Porto Alegre, 14 de fevereiro de 1875). A velha brincadeira despertava, portanto, uma preocupação familiar e social sobre o comportamento das mulheres.

Esmeraldinos e venezianos - "a nata dos moços da nossa sociedade, a boa gente da terra" (FERREIRA, 1970, p. 32) - seriam os condutores dessa reforma de costumes que demarcava papéis de gênero que deveriam ser assumidos na nova festa: aos homens, caberia o protagonismo na criação das sociedades carnavalescas, bem como a ativa participação nos préstitos e na organização dos bailes e desfiles; enquanto para as mulheres foi relegada uma posição de passividade, de espectadoras da festa, sendo delas 
esperada uma estrondosa recepção ou uma manifestação de simpatia pelos festejos executados pelos jovens.

Apesar de terem feito sucesso, influenciando o surgimento de outras sociedades carnavalescas, Esmeralda e Venezianos se retiraram da festa ainda no século XIX, reaparecendo somente no fim daquele carnaval de 1906. Entre os motivos apresentados para sua falência estava a insistência do público feminino na prática entrudesca. $\mathrm{O}$ próprio Venezianos, em seu programa para o carnaval do ano de 1882 , enfatizava a permanência da "perniciosa bisnaga" e, especialmente, o fato de elas "emanarem de delicadas e alvas mãozinhas" que continuavam a contaminar o carnaval (Jornal do Comércio, Porto alegre, 18 de fevereiro de 1882). Embora fosse costumeiro na imprensa da época atribuir ao "zé povinho" a permanência do entrudo, o lamento dos venezianos, criticando o fato das jovens brancas senhoritas da elite, que frequentavam os bailes restritos aos sócios e seus familiares, permanecerem afeitas ao jogo do entrudo, indica que tal distinção social nem sempre se efetivava.

Ao reaparecerem, naquele março de 1906, as tradicionais sociedades apresentaram algumas modificações no que tange a participação das mulheres no festejo: o carnaval "reaparecia sob uma feição acentuadamente feminina" (Correio do Povo, Porto Alegre, 17 de fevereiro de 1907). Com espanto, o jornal Correio do Povo observava que "não restava a menor dúvida: era a linda, a grácil Mulher porto-alegrense que fazia o Carnaval. Por isso vinha ele tão garboso, tão gentil e tão chic. Por isso tinha sido possível o milagre de sua ressurreição (Correio do Povo, Porto Alegre, 17 de fevereiro de 1907).

Além da ampliação dos espaços ocupados pelas mulheres no carnaval proposto pelas referidas agremiações, se observa que houve mudanças na representação das carnavalescas, que deixaram de ser as responsáveis pela contaminação dos festejos de Momo e pela falência de Esmeralda e Venezianos para simbolizarem a ressurreição do carnaval. Desta forma, as mulheres que participavam da festa passaram a ser elogiadas e admiradas, especialmente as rainhas das sociedades, que se tornaram modelos de virtude e beleza, figurando como Marias nos festejos promovidos por essas agremiações ${ }^{4}$. Entre as razões de justificativa para a mudança destaca-se a influência do

\footnotetext{
${ }^{4}$ No carnaval de 1909, a sociedade Esmeralda comparava a sua rainha a Nossa Senhora em versos que eram distribuídos à população durante seu préstito: "Vai passar a Rainha - a nossa Grã Senhora, Virgem Nossa Senhora Imaculada e Casta - qual a santa de um ádro, ao resplendor da aurora, Ou qual mago Santélmo a quem o mar se afasta!/Virgem Nossa Senhora Aparecida em vasta, Nuvem d'ouro e de sonho a qual o sol rubora, Virgem Santa Maria, a cujos pés se arrasta, A multidão que geme e a Sua Graça
} 
positivismo e de sua apropriação em Porto Alegre pela elite da capital, bem como a existência de redes de poder que envolviam a participação de membros do exército, da Brigada Militar e dos quadros do Partido Republicano Rio-grandense nas tradicionais sociedades carnavalescas, o que caracterizava uma certa comunhão de sentidos (político-ideológicos), mesmo na esfera do carnaval, e que parecem ter sido determinantes para essas transformações no reinado de Momo.

De acordo com Joan Scott (1990, p. 14), entre os aspectos que demandam a construção dos gêneros temos, além dos símbolos, os conceitos normativos "expressos nas doutrinas religiosas, educativas, científicas, políticas ou jurídicas" e uma noção de política e referências às instituições, bem como a organização social. Neste sentido, é bom lembrar que, quando do surgimento das sociedades carnavalescas, era o regime monárquico que vigorava no país. Em seu renascimento, contudo, já estamos no período republicano. Com a República, a burguesia trabalhou para criar um modelo de pais e de mães, de homens e mulheres, pautado pelo controle dos corpos e pela disciplinarização dos comportamentos, num combate a práticas e hábitos que atentassem contra ele (PEDRO, 1994).

É ainda importante ressaltar que, quando se dá o ressurgimento destas agremiações, Porto Alegre estava politicamente identificada com ideais positivistas de governo, moldados pelo Partido Republicano Rio-grandense (PRR), que governava o estado e a cidade. Para os positivistas, a questão moral consistia em um dos maiores problemas da humanidade no final do século XIX. Era preciso uma reforma da sociedade, que "a partir de uma nova hegemonia política e social, através de um novo conteúdo, em que a formação da moral e do caráter deveriam ser ensinadas desde os primeiros anos da criança, devendo ser tarefa da família, especialmente da mulher como a primeira educadora, a valorização das primeiras manifestações do altruísmo na criança" (SILVA, p. 10-11).

Saliento também que havia uma reciprocidade entre as elites políticas e os quadros dessas agremiações, pois grande parte dos associados e diretores fazia parte das elites do PRR, bem como grande parte dos membros e diretores destas agremiações estava ligada à Brigada Militar ou ao Exército, ambos sob forte influência do positivismo-castilhismo (KARNIKOWSKI, 2010, p. 96; MCCANN, 2007, p. 40). Desta

implora.../Virgem Santa do Céu! Como ela é bela e moça, E como, feito d'alma, o seu olhar se adoça, E se expande e se estende e sobre nós se reflora!/Ei-la!... Deixem passar o seu ardor singelo! Abram alas!... Avante, ó devotos do belo:Vai passar a Rainha - a Nossa Grã Senhora!” (A Federação, Porto Alegre, 21 de fevereiro de 1909). 
forma, as modificações que ocorreram na festa no que tange às relações de gênero, promoveram distintas representações sobre as mulheres; porém, permaneceram ligadas a uma estratégia de vigilância e controle, imbuída de preceitos ideológicos conservadores e moralizantes, tecidas em meio às redes de poder político, econômico, social, racial e familiar, que legitimava a sua hierarquização.

As Marias do carnaval, portanto, eram representadas pelas filhas desta elite da capital gaúcha, jovens brancas senhoritas que todos os anos eram escolhidas pelas sociedades carnavalescas para serem rainhas da agremiação. Solteiras, entre doze e dezenove anos, exaltadas por sua beleza, graça, candura, fineza, instrução, modéstia e dotes morais, nenhuma outra mulher era mais exaltada do que elas no carnaval. Para as rainhas eram dedicados bailes, tea concerts, exposições de seus retratos, vários eventos que pretendiam consagrar a soberana da agremiação. Por meio do carnaval se difundia o ideal de uma mulher que deveria ser: bonita, mas ingênua; culta, mas modesta; elegante e, sobretudo, moralizada. Essa imagem era veiculada não somente pela fala, como também nas fotografias que eram tiradas das rainhas e expostas nas vitrines das principais ruas da cidade, disponível aos olhos de todos! Eram as Marias o símbolo do carnaval! Embora essas mulheres fossem representantes da elite citadina, esse modelo idealizado para as mulheres poderia não ficar circunscrito às camadas abastadas, difundindo-se entre as populares. Careli, ao investigar inquéritos policiais, processos criminais e crônicas jornalísticas em Porto Alegre, buscando a caracterização da virtude, evidenciou "a forma como determinados comportamentos veiculados como ideais, característicos de um dado grupo social, não ficavam restritos ao mesmo, sendo de formas diversas incorporados por indivíduos alheios a ele" (CARELI, 1997, p. 278). Dito isto, partamos para a história de Elvira Werna Coelho, uma das Marias do carnaval de Porto Alegre.

\section{Elvira Werna Coelho - uma Maria no carnaval de Porto Alegre}

Era carnaval de 1911. A Sociedade Carnavalesca Os Venezianos haveria de apresentar sua rainha. Dias antes, o jornal $O$ Independente fez uma série de publicações, nas quais relatava "a trajetória das grandes e supremas belezas feminis de Porto Alegre" (O Independente, Porto Alegre, 12 de fevereiro de 1911). No dia 12 de fevereiro, a escolhida foi Elvira Werna Coelho: "uma destas jovens, em redor das quais a admiração adeja, como vespas em torno do néctar da flor" (O Independente, Porto Alegre, 12 de 
fevereiro de 1911). A admiração em torno de Elvira seria, segundo o jornal, em função dos seguintes quesitos:

A sua beleza, a supremacia do seu espírito cintilante, a delicadeza do seu trato, os infinitos cambiantes da ternura, que nesta adolescência assume amavios indescritíveis, a sua educação, o seu gênio de encantamento, que joga com esta habilidade despreocupada das grandes naturezas emotivas, feitas para a contemplação tácita dos mortais nos seus instantes de ledos devaneios e seis mares" (O Independente, Porto Alegre, 12 de fevereiro de 1911)

Como salientado anteriormente, partilho da ideia de que a construção dos gêneros se dá através da dinâmica das relações sociais, noção socialmente construída, tanto de masculinidade, quanto de feminilidade. A partir da percepção das diferenças sexuais, há um processo de construção de expectativas do que é ser homem e o que é ser mulher (SCOTT, 1988, p. 32). Juventude, beleza, superioridade de espírito, delicadeza, ternura, foram características definidas pelo imaginário simbólico, expressas pelo meio jornalístico, a partir de expectativas marcadas pelo gênero, na construção das categorias homem/mulher. O jornal elencava, portanto, elementos de uma expectativa social para o que deveria ser uma mulher na Porto Alegre do início do século XX. Uma identidade feminina como norma e padrão a ser seguido, a fim de obter se obter um reconhecimento social.

Outros grupos, que não apresentassem as mesmas características destacadas, poderiam aparecer como estando à margem, desviantes ou inferiores. Foi o caso de duas mulheres que desfilaram no carnaval de 1904 (anterior ao ressurgimento de Esmeralda e Venezianos). Ao descrever suas fantasias, o jornal A Federação, ressaltava que "as duas pestes", "arranjaram-se, simplesmente, de modo que pudessem anunciar a sua mercadoria com toda clareza e evidência" ( $A$ Federação, Porto Alegre, 17 de fevereiro de 1904). De acordo com Sandra Pesavento (1995, p. 62), o crescimento do centro urbano da cidade "passara a oferecer ameaça à moral e aos bons costumes das famílias honradas", que tiveram que conviver com habitantes que "viviam na contramão da ordem instituída e que apresentavam comportamentos desviantes daqueles que a moral burguesa procurava impor", como por exemplo os bêbados, jogadores, vagabundos e as prostitutas. Tal incômodo era evidenciado pelos jornais que apresentavam um desagrado com a participação das prostitutas nos festejos carnavalescos, bem como com sua presença pelas principais ruas da cidade.

$\mathrm{Na}$ virada do século XIX para o XX os jornais publicavam declarações que expressavam uma insatisfação em relação ao reinado de Momo. Declarações de que o 
carnaval era uma festa cada vez mais plebeia, mais abjeta, altamente imoral e que se devia zelar pela moral pública, eram constantes ( $O$ Independente, Porto Alegre, 09 de março de 1905). Era uma festa na qual uma licenciosa libertinagem corrompia a juventude, ameaçava as bases do lar, da família, que era o fundamento do edifício social (O Independente, Porto Alegre, 09 de março de 1905). As críticas da imprensa eram pautadas em argumentos como imoralidade, licenciosidade e promiscuidade social, fundamentadas por uma noção de distanciamento e seleção social, que revelava uma disputa simbólica e material sobre o festejo; a quem pertencia o carnaval? Hierarquias de desigualdades sociais se revestiam de críticas moralistas e conservadoras, a fim de manter a tão almejada ordem social.

Com o propósito de regenerar a festa e livrar a cidade desse quadro de "licenciosa libertinagem", a elite deveria tomar conta das ruas novamente e, por isso, renasceram Esmeralda e Venezianos. Se antes o carnaval da cidade era sintomático de uma "sífilis social" (O Independente, Porto Alegre, 09 de março de 1905), com o renascimento dessas agremiações, ele passou a ser uma exceção nas festas brasileiras: se em outros lugares o festejo era a "consagração das hetairas da flor e do vício" (Correio do Povo, Porto Alegre, 10 de fevereiro de 1910), em Porto Alegre era "um ressumbramento de arte e galanteria, de elegância e moralidade" (Correio do Povo, Porto Alegre, 10 de fevereiro de 1910), pois nele o povo via "passar a donzela encantadora e gentil portadora de um nome respeitado, o cavalheiro qualificado, o escol da sociedade indígena" (Correio do Povo, Porto Alegre, 10 de fevereiro de 1910). Isso fazia com que "o poviléu não se desmanda[sse] na expansão de suas alegrias; não se excede[sse], porque já se acostumou a essa espécie de domínio que a virtude exerce do alto" (Correio do Povo, Porto Alegre, 10 de fevereiro de 1910).

Deste modo, se evidencia que, a partir do renascimento de Esmeralda e Venezianos, marcar a distinção do carnaval em função de seus protagonistas e pela moralidade passou a ser a tônica. De acordo com a doutrina positivista, essa tarefa de regeneração moral da sociedade tinha marcante presença feminina. Neste sentido, o discurso jornalístico destaca que eram as mulheres com "graça e pureza", as jovens das conhecidas famílias quem fazia o carnaval, e não "hetairas da flor e dos vícios". No carnaval do Rio de Janeiro, nos desfiles de suas tradicionais sociedades, as mulheres também apareciam como forte atração popular, sobretudo a partir da década de 1870. Entretanto, aquelas que lá desfilavam eram célebres meretrizes ou as "hetairas da flor e do vício" e não "as boas moças de família", as "donzelas de um nome respeitado" do 
carnaval porto-alegrense. Seus préstitos traziam “'deusas' pouco vestidas e expondo ao público aquelas mulheres de luxo - inacessíveis aos bolsos populares, mas provavelmente frequente em suas fantasias". Este carnaval tido como mais familiar, no qual não eram as prostitutas que desfilavam, só se daria nas menores sociedades carnavalescas, dos subúrbios cariocas, nas quais a presença de moças de família era comum (CUNHA, 2001, p. 147).

Embora fosse "jovem ainda, diríamos quase um botão de rosa a despontar em pleno azul da mocidade", Elvira possuía uma “compleição moral” que "afina[va]-se já com assomos austeros e adoráveis de gravidade, qual flor sensível que ao contato da brisa inimiga, se contraísse, num movimento de infinita graça e pureza" ( $O$ Independente, Porto Alegre, 12 de fevereiro de 1911). Era Elvira uma jovem, pautada por sua aparência moral, um comportamento rígido e sério. Após a publicação desta homenagem, ela estaria plenamente apta a ser a rainha dos Venezianos. O periódico ressaltou em seus atributos aqueles que eram enaltecidos e exigidos das rainhas das sociedades carnavalescas: uma aparência e comportamento moralizado, orientado por sua pureza e graça. Seria ela uma "rainha de indicação e verdade" ( $O$ Independente, Porto Alegre, 12 de fevereiro de 1911). Não era a detentora desse título por mera indicação, pela influência que sua família tinha no seio dessas agremiações, como logo veremos. Embora jovem, estava pronta para simbolizar o carnaval de Porto Alegre:

E quando aqueles heroicos adoradores de Momo, que tanto vitorias já colheram do entusiasmo do povo, fizerem passar, agora em fevereiro, pelas ruas de Porto Alegre sua grácil rainha cercada do cortejo de seus vassalos e da fantasia alegórica de seus caprichos artísticos, então vereis a gentil soberana aclamada e vitoriada pelo povo como um astro que percorre uma trajetória estelar, por entre alas de corações extasiados, pelo fulgor da beleza e a majestade da pompa.

Este é o desejo do $O$ Independente no instante em que presta a gentil soberana dos Venezianos uma homenagem de admiração e simpatia, filhas do alto apreço em que tem as qualidades excelsas da distintíssima adolescente $(O$ Independente, Porto Alegre, 12 de fevereiro de 1911).

A "distintíssima adolescente", ao que tudo indica, nascera em 1894, filha de João da Matta Coelho e de Miguelina de Castro Werna e Bilstein. Tinha um irmão, Ernesto, cinco anos mais velho do que ela ${ }^{5}$ e era neta, por parte de mãe, de Miguel de Castro Werna Bilstein e D. Maria Benedita de Ataíde.

\footnotetext{
5 Além de Elvira, Miguelina e João foram pais de Ernesto e Marieta Werna da Mata Coelho. Ernesto formou-se pela Faculdade de Medicina (hoje uma das unidades de ensino da Universidade Federal do Rio Grande do Sul), em Porto Alegre, em 1911, defendendo a tese Contribuição ao Tratamento da Tuberculose Pulmonar pelas Injeções de Paratoxina (A Federação, Porto Alegre, 08 de janeiro de 1912).
} 
Seu avô foi um conhecido cidadão porto-alegrense. Monarquista ferrenho, membro de uma família ligada à aristocracia imperial ${ }^{6}$, filiado ao Partido Conservador. Proprietário do jornal $O$ Século, foi um importante partícipe do carnaval portoalegrense, tendo sido, inclusive, presidente da sociedade Esmeralda, no ano de 1883.

Por volta da década de 1880, a Esmeralda apresentava problemas para fazer seus festejos. Em função dessa crise, os diretores da agremiação teriam convidado o avô de Elvira para ocupar a presidência da sociedade, a fim de a agremiação poder se beneficiar de sua "influência pessoal" ( $O$ Século, Porto Alegre, 04 de fevereiro de 1883). Em carta, José Leite de Castro, presidente interino da Esmeralda, oficializou o convite, exaltando a benevolência de Werna para com a Esmeralda ao ceder "a sua mimosa e galante filhinha para representar como nossa soberana [e, por isso, queria] a maioria dos sócios eleger V.S. presidente" (O Século, Porto Alegre, 04 de fevereiro de 1883).

Segundo Aquiles Porto Alegre, com a Proclamação da República, cercado de inimigos, Miguel mudou-se para o Rio de Janeiro (PORTO ALEGRE,1920, p. 73-75). Ele viria a falecer em 21 de julho de 1896, três meses após a morte de sua filha Miguelina, que deixava Elvira, com então dois anos de idade, órfã de mãe ${ }^{7}$. No auto de avaliação do inventário de Miguel e Miguelina encontrei dois bens: um imóvel, "uma casa assobradada, na Rua Gel Portinho, $\mathrm{n}^{\circ}$. 10, com três janelas, seu pavimento superior é todo sótão e um grande portão de entrada do pavimento térreo, dividindo-se por um lado com propriedade de João José Pinheiro Junior e pelo outro lado com propriedade de Francisco José Veloso e cuja casa avaliaram os avaliadores dever dar o valor de 20 contos de reis"; e uma ação da "Cia Hidraulica Guaibense, de no. 1790 e cujo ação avaliaram os avaliadores dever dar o valor de 70 mil reis”. José Soares Júnior,

Faleceu em Alegrete por afogamento quando procurava salvar a vida a uma senhora que havia caído ao rio. Marieta faleceu aos 2 anos de idade, em função de uma faringite aguda. (FAMILIARES, entrevista virtual concedida a Caroline P. Leal, fevereiro 2012).

${ }^{6}$ Filho de Ernesto Frederico de Werna Bilsteine Maria do Carmo de Castro Canto e Melo. Seu pai era filho de pais alemães, que vieram junto com corte portuguesa em 1808, veio para o Rio Grande do Sul como vereador. Em São Leopoldo anunciou a construção de uma estrada entre a cidade e Porto Alegre, o que causou constrangimento ao presidente da província, pois não se cogitava tal obra. Foi o primeiro deputado de origem germânica, entretanto não era considerado representante dos colonos. Defendeu a demissão dos engenheiros estrangeiros do governo do estado, advogando em causa própria. Em 1847 foi encarregado de fazer o balizamento da laguna dos Patos, depois da construção de uma estrada entre São Leopoldo e Portão; das pontes do Moinho e do arroio Portão; da desobstrução do rio Jacuí, que durou de 1859 a 1864, com o trabalho de quinze praças da marinha; em 1866 foi encarregado de consertar os faróis Cristóvão Pereira, do Bujuru, Capão da Marca e do Estreito (WEIMER, 2006, p. 151).

7 Miguelina faleceu em 24 de abril de 1896, no Rio de Janeiro (Inventário de Miguelina de Werna Coelho, n. 2335, 1896, Porto Alegre, APERS). 
procurador de João da Matta Coelho (esposo de Miguelina e genro de Miguel), que era o inventariante, mas que se achava no Rio de Janeiro, declarou que:

os mesmos bens de herança se acham relacionados foram avaliados, como se vê, a folhas cito nesse e que sendo a herança devedora a diversos credores que se acham justificando suas dívidas requer que seja levada a praça a casa da rua, sob no. 10, na Rua General Portinho, não só para satisfazer esses pagamentos como também a ter a fazenda do Estado custas do presente inventário. Declarou finalmente o mesmo procurador que o saldo devedor partilhado depois de feito o cálculo dotava a fazenda do Estado (Inventário de Miguelina de Werna Coelho, n. 2335, 1896, Porto Alegre, APERS).

Através desse documento, podemos perceber que Werna morreu possuindo muitas dívidas e que seu genro teve que cuidar de toda a situação. Até mesmo a casa que possuía foi vendida para saldá-las. Sua mulher, provavelmente, teria ido morar com o genro e os netos, corroborando a versão me dada por familiares de que Elvira fora criada pela avó materna, D. Maria Benedita de Ataíde. A casa que possuíam localizavase em uma rua do centro de Porto Alegre, por onde também passava o cortejo carnavalesco. Como vizinho, eles possuíam o Sr. Francisco José Veloso, outro carnavalesco, sócio da sociedade Esmeralda, cuja filha também fora rainha, logo no primeiro ano de renascimento dessa agremiação, em 1906.

A filha de Werna e mãe de Elvira, Miguelina de Castro Werna e Bilstein, nasceu em Porto Alegre, em 15 de dezembro de 1867 (Registro de Batismo da Igreja de Nossa Senhora das Dores, Porto Alegre, Arquivo Histórico da Cúria Metropolitana de Porto Alegre, RS), e também participou das festividades carnavalescas de seu tempo. Ela foi rainha da sociedade Esmeralda, em 1882, aos 14 anos de idade. Em 1886, em oratório particular se casou com João da Matta Coelho (A Federação, Porto Alegre, 30 de novembro de 1886). João foi major da Guarda Nacional (A Federação, Porto Alegre, 29 de novembro de 1909) e, embora tenha sido eleito vereador de Porto Alegre pelos Conservadores, em 1886, juntamente com João Antunes da Cunha Netto, Raphael Gonçalves Ventura, Guilherme Schell e João Ferreira Porto Filho (A Federação, Porto Alegre, 16 de julho de 1886), em julho de 1889, quando ocupava a vice-presidência da Câmara dos Vereadores, aderiu aos republicanos (A Federação, Porto Alegre, 19 de julho de 1889).

Desta forma, quando da Proclamação da República, ele era um dos vereadores que constituíam a Câmara de Porto Alegre, juntamente com João Antunes da Cunha Neto - Presidente, Rafael Gonçalves Ventura, Guilherme Shell, José Domingos da Costa, Bibiano Dias de Castro, Felicíssimo Manoel de Azevedo e Antônio da Azevedo 
Lima. Foi nomeado pelo "governo revolucionário" para compor a Junta Municipal, a fim de "dirigir os negócios da cidade", ao lado de Antônio de Azevedo Lima (A Federação, Porto Alegre, 18 de novembro de 1891). Assim, em novembro daquele ano, assumiu como presidente da junta municipal, substituindo Felicíssimo Manuel de Azevedo (PORTO ALEGRE, 2004). Por solicitação do próprio João, seis meses depois, foi dispensado do lugar de intendente municipal (A Federação, Porto Alegre, 13 de junho de 1892). Foi, deste modo, um dos primeiros chefes municipais do período republicano, governando a cidade entre 21 de novembro de 1891 e 11 de junho de 1892 (BAKOS, 1996, p. 43). Ele, assim como a esposa e o sogro, também era um apreciador do carnaval, só que da sociedade rival: S. C. Os Venezianos. Foi tesoureiro e vicepresidente da mesma ${ }^{8}$.

Fiz esse resgate familiar de Elvira a fim de mostrar o quanto sua história estava entrelaçada com a própria história do carnaval de Porto Alegre. Avô, pai, mãe todos estiveram envolvidos com as sociedades carnavalescas, seja Esmeralda ou Venezianos. Não quero com isso imputar uma coerência artificial (SCHMIDT, 2004, p. 139) à vida de Elvira, a fim de não reforçar uma ilusão biográfica ${ }^{9}$. Minha intenção é tornar visível que ela cresceu em um ambiente que dava importância e participava dos festejos carnavalescos de seu tempo. Isto não significa que em sua trajetória de vida já estivesse predeterminada a "viver o carnaval", pois fazia isto "desde pequena".

Procurei aqui mostrar que "como qualquer indivíduo, a cada momento de suas vidas, tem diante de si um futuro incerto e indeterminado, diante do qual fazem escolhas. Seguem alguns caminhos e não outros" (BOURDIEU, 1996, p. 139) e que, até certo momento, Elvira escolheu seguir o "caminho carnavalesco", aos moldes de avô, pai e mãe, participando ativamente de sua agremiação. Destaco que Elvira representou a sociedade carnavalesca escolhida pelo pai - Os Venezianos. Até porque ela teve pouco contato, tanto com a mãe, quanto com o avô, que eram esmeraldinos, pois eles morreram quando ela era ainda bem pequena. Além disso, seu pai era um membro bem ativo da agremiação e Elvira, provavelmente, cresceu com a presença dos venezianos em sua residência, como por exemplo, quando do aniversário de João da Matta Coelho, os venezianos iam lhe fazer os cumprimentos:

\footnotetext{
${ }^{8}$ João da Matta Coelho foi eleito vice-presidente da Sociedade Carnavalesca Os Venezianos, em 1908, tendo ficado a presidência para Cel. Afonso Massot. Ele já havia sido, também tesoureiro desta associação, em 1882 (O Independente, Porto Alegre, 29 de março de 1908).

${ }^{9}$ Pierre Bourdieu chama de "ilusão biográfica" o engano, a ilusão de se considerar uma vida "[...] como um todo, um conjunto coerente e orientado, que pode e dever ser apreendido como expressão unitária de uma 'intenção' subjetiva e objetiva, de um projeto [...]”' (BOURDIEU, 1996, p. 184).
} 
Sábado passado o furioso Zé-Pereira dos Venezianos foi levar os seus parabéns ao seu vice-presidente João da Matta Coelho por motivo de seu aniversário.

Gentilmente recebidos, foram obsequiados com farta mesa de doces e líquidos, trocando-se por essa ocasião diversos brindes.

Após teve começo animada soirée que durou até alta noite, correndo sempre entre a mais franca cordialidade.

Despediu-se, por fim, a correta mocidade veneziana, entre vivas ao Sr. Matta Coelho, a sua família e sua rainha ( $O$ Independente, Porto Alegre, 13 de fevereiro de 1908).

Antes mesmo de ser rainha da sociedade, Elvira já participava dos desfiles. No ano de 1909, ela saíra numa "magnífica alegoria apresentada com grande propriedade, gosto e perfeição das linhas". O carro A Presa representava uma "donzela surpreendida no bosque por uma enorme serpente, que, preparada para dar-lhe o bote supremo e de faces hiante, e a ainda contida pela graça e pela candura da vítima, figurada pela senhorita Elvira Werna Coelho, filha do nosso amigo João da Matta Coelho" ( $A$ Federação, Porto Alegre, 25 de fevereiro de 1909). Novamente se salientava a graça e candura de Elvira que, representando a presa, foi surpreendida por uma enorme serpente. Deste carro foram distribuídos os seguintes versos:

Neste bosque tão cheio de primores

Senhorita gentil auda passar

Anda, quiça, pensando em seus amores

E uns sonhos cor de rosas, a sonhar.

Distraída vagueia pelas flores,

Pelas flores silvestres a cismar

E súbito ela vê, por entre horrores

A bíblica serpente a fitar.

Estaca, para e toda se apavora

Ao ver num tronco lá daquela flora

A serpente a mirar-lhe a sobranceira.

Quer fugir, quer correr, a desditosa

Mas é tarde, a serpente impiedosa,

Em um segundo a torna prisioneira 'A Federação, Porto Alegre, 25 de fevereiro de 1909).

O verso descreve uma jovem romântica, com o pensamento nos amores e nos sonhos, que, audaciosamente, passou pelo bosque. Lá se deparou com a serpente bíblica, que a fez prisioneira, mesmo querendo ela fugir e correr. Elvira incorpora aqui o papel da jovem sonhadora, presa pela serpente. A cobra é a representação daquilo que seria bom, enquanto proibido. É o ser que engana, trapaceia.

Dois anos após essa apresentação, em 1911, era a vez de Elvira ocupar o lugar de soberana dos venezianos. Ao longo de seu reinado, ela teria uma extensa agenda a 
cumprir, sendo muitas as festividades a envolver a rainha da agremiação: festa de apresentação, reuniões em sua casa, visitas à caverna (local de encontro veneziano), inauguração de seu retrato. As atenções se voltariam todas para ela.

Em janeiro, Os Venezianos fizeram a apresentação de sua rainha, no Clube Caixeiral: "às nove horas, o clarim-mor anunciou a aproximação". Elvira "cuja entrada triunfal teve imponente caráter" foi recebida "à porta, pela diretoria, tocando duas bandas de música alegres marchas e, ao ar, subindo uma girândola de foguetes”. O presidente da sociedade, tenente coronel Afonso Massot lhe deu o braço e a apresentou ao público (A Federação, Porto Alegre, 13 de janeiro de 1911). Ainda em janeiro, após fazerem um passeio pela cidade, no qual " 174 senhoritas trajando lindas toilettes com as cores daquela sociedade carnavalesca", os venezianos se reuniram na casa de sua soberana: "senhorita Elvira Werna Coelho, e seu pai, major João da Matta Coelho, obsequiaram com uma mesa de doces e bebidas os diretores e os sócios da sociedade Venezianos" (Correio do Povo, Porto Alegre, 30 de janeiro de 1911). Ou ainda na inauguração da caverna veneziana, na qual ela foi recebida "com todas as honras do estilo. A galante soberana, ao penetrar no recinto, recebeu estrondosa manifestação de aplausos, vivas e confete (A Federação, Porto Alegre, 05 de janeiro de 1911). Observemos que a presença das rainhas - no caso aqui em análise, de Elvira - é sempre pautada por um ar de distinção: elas são galantes, tem supremacia de espírito, beleza e moral. Sua presença nos eventos era o ápice dos festejos.

Entre os eventos mais importantes, que faziam parte da agenda das soberanas, estava a inauguração da exposição de seus retratos, normalmente, nos ateliês mais reconhecidos da cidade. Jacinto Ferrari e Virgílio Calegari foram os responsáveis por retratarem rainhas esmeraldinas e venezianas, respectivamente.

De acordo com Alexandre Santos (1998, p. 29-30), o início do regime republicano no Rio Grande do Sul veio acompanhado pelo aburguesamento dos costumes e "encontrou posição privilegiada no signo fotográfico [...] a materialização imagética do conceito de modernidade, sustentada no efêmero e na imortalização do instante" Frequentar um estúdio fotográfico era a incorporação do signo da modernidade. O retrato fotográfico dava a ver o indivíduo e a prática distintiva de um determinado grupo, que carregava consigo diversos signos. Desta forma, no dia em que as fotografias das soberanas fossem exibidas nas vitrines, era promovida uma verdadeira festa, cercada de muita pompa, contava com a presença dos membros das diretorias e de bandas musicais. Apesar da mostra de fotografias dos artistas em estabelecimentos ser 
uma prática comum a esses comércios, a intenção de dar a ver a rainha sendo retratada por um ilustre fotógrafo e promover uma festa a fim de exibir esse signo, pode ser interpretado como mais um sinal na tentativa de distinção do carnaval promovido por Esmeralda e Venezianos e das mulheres que o representavam.

Além das vitrines, os jornais publicados pelas próprias sociedades, Esmeralda e Venezianos, e que eram distribuídos durante os desfiles, estampavam na primeira página o retrato da soberana ${ }^{10}$. Eram também publicados nos demais periódicos da capital, tanto que o jornal $O$ Independente procurava, na semana de carnaval, publicar as fotos das rainhas das sociedades, com breves descrições a seu respeito: Elvira "outra pérola de artístico lavor que reúne a limpidez do orvalho, a doçura do lírio" - referência à natureza associadas às qualidades das rainhas são descrições costumeiras neste momento de renascimento destas agremiações - teve o seguinte retrato publicado pelo referido jornal:

Figura 1: Retrato de Elvira Werna Coelho, rainha dos Venezianos, 1911

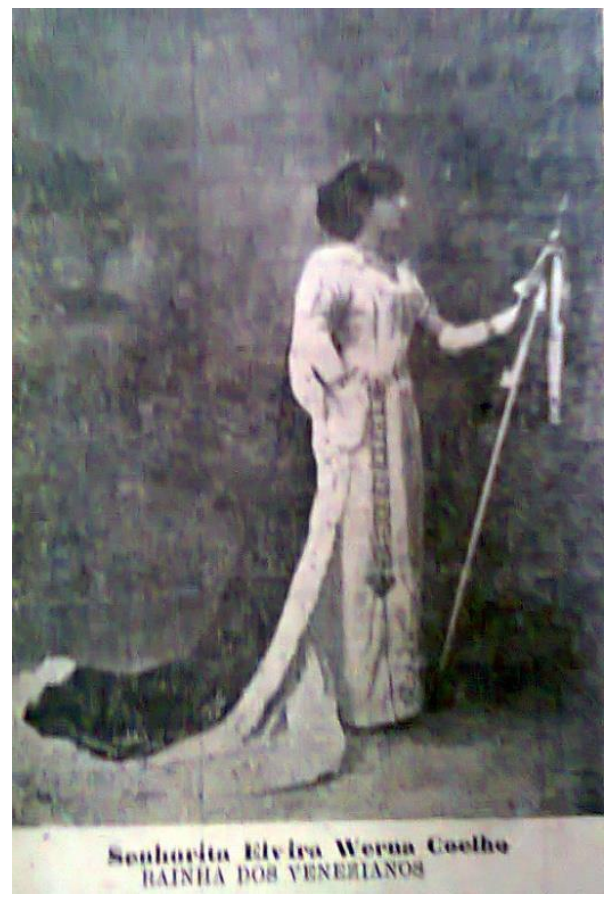

Fonte: O Independente, Porto Alegre, 21 de fevereiro de 1911.

Diferentemente das outras rainhas venezianas, Elvira foi retratada pelo atelier Ferrari, ao invés de Calegari. Apesar do bom relacionamento entre as agremiações, a identificação de uma sociedade carnavalesca com um ou outro fotógrafo não deixava de

10 "Também foi distribuído o jornal Esmeralda, como retrato da rainha na primeira página, e contendo espirituosa e variada colaboração" (A Federação, Porto Alegre, 21 de fevereiro de 1909). 
ser uma competição à parte. De acordo com Santos, Jacinto Ferrari foi quem "se constituiu em ator principal de uma rivalidade tácita entre a família Ferrari e Calegari, no que se refere ao ofício da fotografia na aurora do século XX” (SANTOS, 1998, p. 29). Mesmo não havendo um confronto direto entre eles, em vários momentos "da trajetória profissional dos dois fotógrafos a sua disputa implícita pelo prestígio profissional é notória. [...] quando um se destacava em algo, o outro trazia uma novidade" (SANTOS, 1998, p. 31). Assim, a identificação de Calegari com a Venezianos e de Ferrari com a Esmeralda, pode ser entendida como mais uma etapa desta tácita competição: quem retratava a melhor rainha?

Elvira, como neta de Miguel de Werna, era descendente de um irmão da Marquesa de Santos, o $2^{\circ}$ Visconde de Castro, João de Castro e Melo. Isso parece ter sido bem importante nas memórias de sua família, haja vista ter sido a primeira informação que obtive a seu respeito: "ela é descendente direta da Marquesa de Santos" (FAMILIARES. Entrevista virtual concedida a Caroline P. Leal. Porto Alegre, fevereiro de 2012). Apesar de ser um parentesco bem distante, tal informação também aparece no jornal $O$ Independente, como sinal de distinção de seu comportamento, o poder da graça que teria sido lhe dada pela soberania de seus ascendentes:

Há nesta juventude, como numa corda passível de múltiplos acordes, inumeráveis liames de sedução, fluidos de ignotas admirações, que ela prende e jugula com esta confiança ingênua e certeira de quem conhece a soberania de seus ascendentes, o poder da graça que lhe foi doada pela natureza ( $O$ Independente, Porto Alegre, 12 de fevereiro de 1911).

Segundo relato de parentes, Elvira "era uma dama. Pessoa de fino trato" (FAMILIARES. Entrevista virtual concedida a Caroline P. Leal. Porto Alegre, fevereiro de 2012). Neste ponto devemos lembrar que trabalho com as "memórias dos informantes" (AMADO, 2000) e que, como qualquer outra fonte, é necessário "recompor as reminiscências por ele registradas" (THOMSON, 1997, p. 1). Aqui, entendo por memória "a propriedade de conservar certas informações, por meio de um conjunto de funções psíquicas e cerebrais" (FREITAS, 2002, p. 59), sendo composta de seletividade e esquecimentos. Nesse processo de rememoração do passado, deve-se levar em conta que a "fonte" o refez e o reconstruiu com seus valore atuais, pois o passado "não sobrevive 'tal como foi', porque o tempo transforma as pessoas em suas percepções, ideias, juízos de realidade e de valor" (FREITAS, 2002, p. 65). Além disso, como afirma Bosi (1994, p. 280), “lembrar-se é uma ação coletiva, pois, embora o 
indivíduo seja o memorizador, a memória somente se sustenta no interior de um grupo”. Dessa forma, a reconstrução do passado dependerá da integração ao grupo social com o qual o indivíduo compartilha de suas experiências.

Portanto, nas memórias familiares de Elvira, ficou registrado que, apesar de ter sido criada para ser uma dama ${ }^{11}$, o grande problema de sua vida teria sido o seu casamento. Em $1^{\circ}$ de março de 1924, ela se casou com Mathias Octávio Roxo (CERTIDÃO de Casamento. Cartório de Registro Civil da $1^{\text {a }}$ Zona de Porto Alegre, RS, março de 1924). Conhecido como Mathiasinho, nasceu em 30 de setembro de 1894, no Rio de Janeiro. Filho de Mathias Octávio Roxo e de Eugenia de Negreiros Roxo, irmão gêmeo de Joaquim Alberto, teria falecido em Porto Alegre (NOBRE, 1998) e era considerado um membro desgarrado da família, pois foi viver em Vacaria, no Rio Grande do Sul, onde foi juiz e promotor público dessa comarca, enquanto sua família era radicada entre Rio de Janeiro e São Paulo (NOBRE, Eduardo Dias Roxo. Relato virtual concedido a Caroline P. Leal, fevereiro de 2012; CERTIDÃO Cartório da Direção do Foro da Comarca de Vacaria, Livro de Registro Histórico, 27 de agosto de 1930).

De acordo com Ismério (2007, p. 10), no Rio Grande do Sul, do início do século passado, a fim de que as moças desempenhassem exemplarmente seu papel, elas recebiam alguns conhecimentos básicos, "principalmente as chamadas prendas domésticas, tais como costurar, bordar, fazer rendas e os serviços da casa, que lhes era transmitidos por suas mães. Quando fossem para a escola aprenderiam essas matérias, oferecidas no currículo normal, além de tocar instrumentos musicais, como violino, acordeom e piano". Essa foi, justamente, a descrição nos dada de Elvira: "ela tocava piano como ninguém" (FAMILIARES. Entrevista virtual concedida a Caroline P. Leal. Porto Alegre, fevereiro de 2012). Seu pai, aliás, figurava entre os 15 compradores portoalegrenses - juntamente com o Presidente do Estado, Borges de Medeiros - dos pianos Schiedmayer, nas propagandas da marca no ano de 1907 (A Federação, Porto Alegre, 23 de dezembro de 1907). Contudo, o casamento com Mathias fez com que o curso de

\footnotetext{
${ }^{11}$ Aos 12 anos Elvira era leitora da revista O Tico-Tico - Jornal das Crianças, publicada no Rio de Janeiro. Além das histórias infantis e passatempos, a revista incluía temas da História do Brasil e contos literários em capítulos seriados. Algumas obras estrangeiras como as de autoria de Mark Twain, Robert Louis Stevenson, Julio Verne, Miguel de Cervantes, William Shakespeare, Jonathan Swift, Daniel Defoe, entre outros, também foram publicadas (ALMEIDA, 2015). Elvira participava de concursos promovidos pela revista, enviando soluções corretas para os desafios propostos, como no concurso no 65 , de 1906 ( $O$ Tico-Tico, Rio de Janeiro, 19 de setembro de 1906). Isso também evidencia a posição de classe ocupada no grupo social por Elvira, num período em que poucas pessoas tinham acesso a leituras vinda da capital do país.
} 
sua vida tivesse sido alterado. Segundo o relato, ele a teria abandonado e, sem dar explicações, ao que indica, teria voltado para São Paulo. Apesar de ser de uma importante família, era um homem desregrado, dado a jogos e vícios. Ela, a dama bem nascida e educada, teve que "ir à luta" para criar a família (FAMILIARES. Entrevista virtual concedida a Caroline P. Leal. Porto Alegre, fevereiro de 2012).

Elvira e Mathias se casaram em 1924, ambos com trinta anos (apesar da certidão apontar Elvira com 25 anos). Tiveram quatro filhos: Lourdes Maria Coelho Roxo, nascida em 1926; Paulo de Tarso Coelho Roxo, nascido em 1933 e falecido em 1998; João Batista Coelho Roxo, nascido em 1935 e Pedro Evangelista Coelho Roxo, nascido em 1941 (NOBRE, 1998). Se as datas de nascimento dos filhos estão corretas, quando Pedro Evangelista nasceu, Elvira tinha 47 anos. Desta forma, não se concretiza a ideia de que ele a abandonou muito cedo e ela teve que trabalhar para sobreviver, pois 17 anos após o casamento eles ainda teriam um filho. O que pode ter ocorrido é ele ter morado em outra cidade, como Vacaria, por exemplo, onde sabemos ter sido ele juiz, em 1930, já casado com Elvira. Talvez ele morasse por lá e ela em Porto Alegre? Isso, contudo, não impediu que continuassem casados e com uma família em comum.

Elvira foi funcionária da Secretaria da Educação e Saúde Pública do Estado do Rio Grande do Sul e se aposentou como funcionária pública ${ }^{12}$. O real motivo que levou Elvira a trabalhar fora, por ora não compreenderemos, nem como se construiu a memória de que teria sido o abandono do marido a mudar o curso de sua vida. Conhecemos, contudo, que havia discursos que salientavam a "imagem da mulher como responsável pelas atividades da casa e o zelo pela família; deveria ser realmente a rainha do lar e anjo tutelar" (ISMÉRIO, 2007, p. 6). E, de acordo com Ismério (2007, p. 6), uma mulher que "optasse por trabalhar fora, cairia em uma desordem moral, pois deixaria de exercer sua verdadeira vocação para ocupar-se de atividades prescritas ao homem, indo contra sua natureza". Ao tomar tal atitude e "ir à luta para criar a família", Elvira estava destoando do modelo para o qual ela havia sido criada, bem como do modelo que ela representou, ao ser escolhida como rainha da sociedade carnavalesca venezianos, residindo aí, talvez, indícios para explicar meus questionamentos.

\footnotetext{
12 Em 1930 “foi criado o Ministério da Educação e Saúde Pública. A nível estadual, houve a criação da Secretaria de Educação e Saúde Pública (1935) e, dentro desta secretaria, a criação do Departamento Estadual de Saúde (1938). Porém, dois anos depois de ser oficializado (1940), este departamento foi desligado da Secretaria de Educação, passando a estar diretamente subordinado ao governador" (ALVES, 2009, p. 2).
} 
Elvira morreria em 1981. Vivia ainda em Porto Alegre, residindo na Rua Duque de Caxias, pela qual seu cortejo percorreu naqueles idos de 1911. Contudo, essa memória de seu passado carnavalesco não estava presente na família que construiu. Apesar de ela, seus pais e avós serem apreciadores do carnaval, seus filhos, netos, sobrinhos, não sabiam da relação de Elvira com tal festejo. Como todo ser humano escolhe seu caminho e a vida não é feita de coerências, Elvira escolheu se afastar e não prosseguir nessa ligação de sua família com a história do carnaval de Porto Alegre.

\section{Considerações Finais}

Ao analisar a trajetória de vida de Elvira, pode-se observar uma estreita circularidade entre os espaços público e privado, ou seja, o núcleo familiar e o associativo, a casa e a sociedade. A começar pela indicação e escolha da soberana, onde o peso da autoridade paterna e do prestígio familiar exercia um papel determinante. Em várias ocasiões, o espaço do lar era "invadido" pela folia, quando as sociedades carnavalescas iam à casa das rainhas para agraciá-la com alguma honra ou informá-las da escolha. Além disso, se verifica uma teia de relacionamentos nos quais se inseriam os carnavalescos: vizinhos - como Francisco Veloso e Miguel de Werna - ou até mesmo de namoros e casamentos, como o de Miguelina e João da Matta Coelho, pais de nossa soberana.

Através da trajetória de vida de Elvira, busquei trazer à luz algumas questões no que se refere à transformação que ocorreu no carnaval de Porto Alegre, a partir do renascimento de Esmeralda e Venezianos, em relação à participação das mulheres nos festejos. De Evas pecadoras, as mulheres passaram a figurar como Marias recatadas e redentoras do carnaval. Elvira, por exemplo, foi reverenciada não só por sua juventude e beleza, mas também por sua graça e pureza, possuidora de uma "compleição moral". A influência do positivismo e de sua apropriação em Porto Alegre pela elite da capital e das redes de poder estabelecidas, que envolviam a participação de membros do exército, da Brigada Militar e dos quadros do Partido Republicano Rio-grandense (PRR), nas tradicionais sociedades carnavalescas estão entre os fatores que nos ajudam a compreender essa transformação. O pai de Elvira, por exemplo, além de ser major, foi intendente de Porto Alegre e importante membro do Partido Republicano Riograndense.

Embora os participantes do carnaval venezianos fossem representantes da elite citadina, podemos supor que havia uma difusão dos valores expressos em seus discursos por diferentes grupos sociais. Os desfiles e vários eventos promovidos por essas 
agremiações, como a exposição do retrato das soberanas, por exemplo, ao estarem disponíveis aos olhos de todos, eram contemplados não só pelas elites, como por outros segmentos sociais, contribuindo para a formatação da imagem do que deveria ser uma mulher na Porto Alegre do início do século XX.

No entanto, se por um lado havia um discurso patriarcal, no qual se percebe um reforço das hierarquias dominantes de masculino sobre o feminino durante as festas de carnaval; por outro, ao olhar para a trajetória de vida de uma rainha, encontrei uma mulher que no curso de sua vida não se amoldou aos espaços e lugares destinados a ela. Elvira parece ter casado bem tarde para os padrões da época, viveu separada do marido e não ficou a cuidar do lar. Criada para ser uma "dama”, instruída nas letras e nas artes, foi para a rua, trabalhar, mostrando as margens de liberdade de escolha dos indivíduos diante dos sistemas normativos e das possibilidades de sua época.

\section{Referências}

\section{Fontes}

Arquivo Histórico da Cúria Metropolitana de Porto Alegre, Rio Grande do Sul.Registro de Batismo da Igreja de Nossa Senhora das Dores de Miguelina Werna, 1867.

Arquivo Histórico de Porto Alegre Moysés Vellinho. Hemeroteca. Independente, Porto Alegre, 09 de março de 1905, 13 de fevereiro de 1908, 29 de março de 1908, 12 de fevereiro de 1911.

Arquivo Público do Estado do Rio Grande do Sul. Inventário de Miguelina de Werna Coelho, n. 2335, Porto Alegre, 1896.

Biblioteca Nacional. Hemeroteca digital. O Tico-Tico, Rio de Janeiro, 19 de setembro de 1906.

Cartório da Direção do Foro da Comarca de Vacaria, Rio Grande do Sul. Livro de Registro Histórico. CERTIDÃO de exercício da função de Juiz Distrital a Octávio Mathias Roxo, folha 20, 27 de agosto de 1930.

Cartório de Registro Civil da $1^{\text {a }}$ Zona de Porto Alegre, Rio Grande do Sul. CERTIDÃO de Casamento Mathias Octávio Roxo e Elvira Werna Coelho, março de 1924.

FAMILIARES. Entrevista virtual concedida a Caroline P. Leal. Porto Alegre, fevereiro de 2012.

Museu de Comunicação Hipólito José da Costa. Coleção de Jornais e Revistas. A Federação, Porto Alegre, 19 de julho de 1889, 16 de julho de 1886, 30 de novembro de 1886, 18 de novembro de 1891, 13 de junho de 1892, 21 de fevereiro de 1909, 25 de 
fevereiro de 1909, 29 de novembro de 1909, 05 de janeiro de 1911, 13 de janeiro de 1911,08 de janeiro de 1912.

Museu de Comunicação Hipólito José da Costa. Coleção de Jornais e Revistas. A Reforma, Porto Alegre, 08 de fevereiro de 1875, 14 de fevereiro de 1875, 18 de fevereiro de 1875.

Museu de Comunicação Hipólito José da Costa. Coleção de Jornais e Revistas. Correio do Povo, Porto Alegre, 17 de fevereiro de 1907, 10 de fevereiro de 1910, 30 de janeiro de 1911.

Museu de Comunicação Hipólito José da Costa. Coleção de Jornais e Revistas. Jornal do Comércio, Porto alegre, 18 de fevereiro de 1882.

Museu de Comunicação Hipólito José da Costa. Coleção de Jornais e Revistas. $O$ Século, Porto Alegre, 04 de fevereiro de 1883.

NOBRE, Eduardo Dias Roxo. Relato virtual concedido a Caroline P. Leal, fevereiro de 2012.

Registro Civil das Pessoas Naturais da $4^{\mathrm{a}}$ zona, Porto Alegre, Rio Grande do Sul. Livro de Registro de Óbito. CERTIDÃO de Elvira Coelho Roxo, $n^{\circ}$ C-52, folha n⿳⺈冂大 35 , 21 de abril de 1981 .

\section{Bibliografia}

ALBERTI, Verona. Manual de História Oral. Rio de Janeiro: FGV, 2004.

ALMEIDA, Cintia Borges de. Para a Petizada Inocente: encanto, diversão e lições de conduta na Revista O Tico-Tico (1905-1910). Revista Teias, Rio de Janeiro, v. 16, n. 41, p. 54-71, abr./jun. -2015.

ALVES, Gabrielle Werenicz. As políticas para a saúde pública no Rio Grande do Sul 1928/1945. IV Mostra de Pesquisa da Pós-Graduação, PUCRS, 2009.

AMADO, Janaína; FERREIRA, Marieta de Moraes. Usos e Abusos da História Oral. Rio de Janeiro, FGV, 2000.

BAKOS, Margaret. Porto Alegre e seus Eternos Intendentes. Porto Alegre: EDIPUCRS, 1996.

BOSI, Ecléa. Memória da Psicologia. Estudos Avançados, São Paulo, v. 8, n.22, 1994.

BOURDIEU, Pierre. A ilusão biográfica. Usos e abusos da História Oral. In: AMADO, Janaína; FERREIRA, Marieta Moraes (org.). Usos e abusos da história oral. Rio de Janeiro: Editora da Fundação Getúlio Vargas, 1996.

CARELI, Sandra. Texto e contexto: Virtude e Comportamento Sexual Adequado às Mulheres na Visão da Imprensa Porto-Alegrense da Segunda Metade do Século XIX. Dissertação (Mestrado em História) UFRGS, Porto Alegre, RS, 1997. 
CATTANI, Helena Cancela. G.R.E.S. Porto Alegre: o processo de cariocalização do carnaval de Porto Alegre (1962-1973). Dissertação (Mestrado em História), UFRGS, Porto Alegre, 2015.

CUNHA, Maria C. P. Ecos da Folia: uma história social do carnaval carioca entre 1880 e 1920. São Paulo: Companhia das Letras, 2001.

FERREIRA, Athos Damasceno. O Carnaval porto-alegrense no século XIX. Porto Alegre: Livraria do Globo, 1970.

FREITAS, Sonia Maria de. História Oral: possibilidades e procedimentos. São Paulo: Humanitas, 2002.

GALLI, Laura Spritzer. Um longo caminho até o Porto Seco: lutas e disputas por espaço no carnaval de Porto Alegre (1994-2004). Dissertação (Mestrado em História), UFRGS, Porto Alegre, 2019.

GERMANO, Iris. Rio Grande do Sul, Brasil e Etiópia: os negros e o carnaval de Porto Alegre nas décadas de 1930 e 40. Dissertação (Mestrado em História), UFRGS, Porto Alegre, 1999.

ISMÉRIO, Clarice. ISMÉRIO, Clarice. As representações do feminino na educação riograndense segundo o discurso positivista (1889-1930). Revista Eletrônica História em Reflexão, Dourados, Vol. 1, n. 1, Jan/Jun, 2007.

KARNIKOWSKI, Romeu Machado. De exército estadual à polícia-militar: o papel dos oficiais na policialização da Brigada Militar (1892-1988). Tese (Doutorado em Sociologia), UFRGS, Porto Alegre, RS, 2010.

LAZZARI, Alexandre. "Certas coisas são para que o povo não as faça”: carnaval em Porto Alegre, 1870-1915. Dissertação (Mestrado em História), UNICAMP, Campinas, 1998.

LEAL, Caroline P. As Mulheres no Reinado de Momo: lugares e condições femininas no carnaval de Porto Alegre (1869-1885). Dissertação (Mestrado em História), PUCRS, Porto Alegre, 2008.

Festas carnavalescas da elite de Porto Alegre: Evas e Marias nas redes do poder (1906-1914). Tese (Doutorado em História), PUCRS, Porto Alegre, 2013.

MCCANN, Frank D. Soldados da Pátria - História do Exército brasileiro 1889-1937. São Paulo: Cia das Letras, 2007.

NOBRE, Eduardo Dias Roxo. João Roxo e seus Descendentes. De Pensalves para o Brasil. São Sebastião da Grama-SP: São Sebastião Editora e Gráfica Lda, 1998.

PEDRO, Joana Maria. Mulheres honestas e mulheres faladas: uma questão de classe. Florianópolis: Ed da UFSC, 1994.

PESAVENTO, Sandra. O Cotidiano da República: elite e povo na virada do século. Porto Alegre: Ed. Da Universidade/UFRGS, 1995. 
PORTO ALEGRE, Achylles. Flôres entre ruínas. Porto Alegre: Oficinas Gráficas Wiedemann \& Cia, 1920.

PRIORE, Mary Del. Biografia: quando o indivíduo encontra a história. Topoi, Rio de Janeiro, v. 10, n. 19, jul.-dez. 2009.

ROSA, Marcus Vinícius de Freitas. Quando Vargas caiu no samba: um estudo sobre os significados do carnaval e as relações sociais estabelecidas entre os poderes públicos, a imprensa e os grupos de foliões em Porto alegre durante as décadas de 1930 e 1940. Dissertação (Mestrado em História), UFRGS, Porto Alegre, 2008.

SANTOS, Alexandre. Calegari. In: ACHUTTI, Luiz Eduardo. Ensaios sobre o fotográfico. Porto Alegre: Unidade Editorial: Prefeitura Municipal de Porto Alegre, 1998.

SCHMIDT, Benito Bisso. Grafia da Vida: reflexões sobre a narrativa biográfica. História UNISINOS, São Leopoldo, v. 8, n. 10, jul/dez. 2004.

SCOTT, Joan. W. Gender and the politics of history. New York: Columbia Univ. Press, 1988.

Gênero: uma categoria de análise histórica. Educação e Realidade, Porto Alegre, v.16, n.2, jul/dez 1990.

SILVA, João Carlos da. Utopia Positivista e Instrução Pública no Brasil. Revista HISTEDBR On-line, Campinas, n. 16, p. 10-16, dez. 2004.

SOHIET, Rachel. Mulheres e Biografias. Significados para a História. Locus - Revista de História, Juiz de Fora, vol. 9, n.1, p. 33-48, 2003.

STEYER, Fábio Augusto. Reflexões sobre a história do jornalismo no Rio Grande do Sul: uma experiência de pesquisa. Anais I Encontro de História da Mídia. UNICENTRO, Guarapuava/PR, 2010.

THOMSON, Alistair. Recompondo a Memória: Questões sobre a relação entre História Oral e a Memória. Proj. História, São Paulo, n.15, abril 1997.

VARGAS, Anderson. Usos da Antiguidade: imprensa, civilização e decadentismo no sul Brasil Republicano. Liber Intellectus, v. 2, 2007.

WEIMER, Günter. Arquitetos e construtores Rio-Grandenses na Colônia e no Império. Santa Maria: Editora da UFSM, 2006.

Artigo recebido em 17 de abril de 2020. Aprovado em 25 de novembro de 2020. 